\title{
OPINION
}

\section{Randomized studies of PSA screening: an opinion}

\author{
Oliver Sartor
}

Asian Journal of Andrology (2011) 13, 364-365; doi:10.1038/aja.2011.12; published online 28 February 2011

$\mathrm{T}$ he issue of prostate cancer screening with prostate-specific antigen (PSA) has been contentious for nearly two decades due to lack of data from randomized trials, but that has now changed. A brief review of the available data is warranted as there is finally some clarity on this critically important topic. Knowing what to ignore, as well as what to focus on, is critical for understanding the current data.

The Prostate, Lung, Colorectal, and Ovarian (PLCO) Cancer Screening trial published last year in the New England Journal of Medicine ${ }^{1}$ was too poorly conducted to have credibility in an 'intent-totreat' analysis. It was estimated that about $52 \%$ of the 'control' group had PSA testing during the trial. Further, approximately $44 \%$ of the men in each study group had undergone one or more PSA tests at baseline. It was interesting that the authors noted that men with two or more PSA tests at baseline had a 25\% lower prostate cancer mortality rate as compared to those not tested. During the course of the trial, about $85 \%$ of men in the 'screened' population had documented PSA testing and $15 \%$ did not. Compliance is never perfect in clinical trials, but the combination of $85 \%$ compliance in the 'screened group' and 52\% contamination in the 'control' group combined with $44 \%$ of men having testing at baseline does not allow for credible conclusions. A brief overview of the 'control' group's cancer stage at presentation indicates that it was dramatically distinct from that observed in the pre-PSA era. ${ }^{2}$ The PLCO trial was not a comparison between screened and unscreened populations and should not be interpreted as such.

The European Randomized Study of Screening for Prostate Cancer (ERSPC) study,

Departments of Medicine and Urology, Tulane Medical School, New Orleans, LA, USA

Correspondence: Dr O Sartor, (osartor@tulane.edu)

Received: 16 January 2011; Accepted: 22 January 2011 ;

Published online: 28 February 2011 also published in the New England Journal of Medicine ${ }^{3}$ demonstrated a modest but statistically distinct prostate cancer-specific survival benefit for PSA screening using and 'intent-to-treat' analysis $(\mathrm{HR}=0.8,95 \% \mathrm{CI}$ : $0.65-0.98$ ) after a median of 9 years of follow-up in men aged 55-69 years (median: 60.1). Not surprisingly, more benefit was seen in men actually having had PSA testing $(\mathrm{HR}=0.73,95 \% \mathrm{CI}: 0.56-0.90)$. Analysis of Göteborg participants ${ }^{4}$, consisting of younger men (range: 50-64 years, median age: 56 years) with a longer follow-up (14 years), indicated a much larger advantage of PSA testing $(\mathrm{HR}=0.44,95 \% \mathrm{CI}: 0.28-0.68)$. In my mind, there is no question that PSA screening, followed by effective treatment, can decrease the risk of dying from prostate cancer if the screening is performed in men young enough to benefit from treatment.

Saving lives from prostate cancer is only one part of the equation, harms from screening and treatment need to be considered as well. From the randomized PSA screening studies, we know that groups undergoing PSA testing have significantly more cancers detected $(8.2 \%$ of 'screened' versus $4.8 \%$ of 'unscreened' men in the ERSPC study). Many, if not most, of the PSA-detected cancers are clinically insignificant. We know from the ERSPC study that PSA screening leads to substantial overdetection of low-risk cancers. At the time of the ERSPCA report, ${ }^{3}$ it was estimated that 48 additional cases of prostate cancer would need to be treated to prevent one death.

From randomized trials of treatment versus no treatment, even in unscreened populations, the vast majority of men with prostate cancer will not die from it. In the Scandinavian Prostate Cancer Group-4 randomized study, the cumulative incidence of prostate cancer death at 12 years was $12.5 \%$ in the radical prostatectomy group and $17.9 \%$ in the watchful waiting group. ${ }^{5}$ For PSA-screened men, the risk of death from prostate cancer would be predicted to be even smaller given the potential for lead time biases associated with early detection. Extrapolating the results from the Scandinavian Prostate Cancer Group-4 randomized trial to a contemporary screened population is conjectural.

What happens to men with prostate cancer in clinical practice? Though globally the answers are uncertain, in the United States almost all patients are currently treated with potentially morbid therapies. ${ }^{6}$ Surveillance is uncommonly utilized. A recent registry indicates that over $90 \%$ of men with 'low-risk' cancers are actively treated. ${ }^{6}$ Iatrogenic and unnecessary sexual and urinary dysfunctions are a direct consequence of overtreatment of prostate cancer. Treatment is more common than can be justified on the basis of the available data for many patients. Our patients deserve better.

Prostate cancer is a highly heterogeneous disease and until clinicians are better at matching treatment recommendations with the risk of disease-related morbidity and mortality, PSA screening may cause more harm than benefit in the average patient. I am not saying that PSA testing should not be used, I get my own PSA annually and will continue to do so, I am simply hopeful that more clinicians will risk-stratify their patients carefully and offer surveillance for those men unlikely to benefit from aggressive therapy.

1 Andriole GL, Crawford ED, Grubb RL 3rd, Buys SS, Chia D et al.; PLCO Project Team. Mortality results from a randomized prostate-cancer screening trial. N Engl J Med 2009; 360: 1310-9.

2 Mettlin CJ, Murphy GP, Ho R, Menck HR. The National Cancer Data Base report on longitudinal observations on prostate cancer. Cancer 1996; 77: 2162-6.

3 Schröder FH, Hugosson J, Roobol MJ, Tammela TL, Ciatto $S$ et al. ERSPC Investigators. Screening and prostate-cancer mortality in a randomized European study. N Engl J Med 2009; 360: 1320-8.

4 Hugosson J, Carlsson S, Aus G, Bergdahl S, Khatami A et al. Mortality results from the Göteborg 
randomised population-based prostate-cancer screening trial. Lancet Oncol 2010; 11: 725-32.

5 Bill-Axelson A, Holmberg L, Filén F, Ruutu M, Garmo H et al. Scandinavian Prostate Cancer Group Study
Number 4. Radical prostatectomy versus watchfu waiting in localized prostate cancer: the Scandinavian prostate cancer group-4 randomized trialJ Natl Cance Inst. 2008; 100: 1144-54.
6 Cooperberg MR, Broering JM, Carroll PR. Time trends and local variation in primary treatment of localized prostate cancer. J Clin Oncol 2010; 28 1117-23. 